\title{
Serum cytokine responses in Rickettsia felis infected febrile children, Ghana
}

\author{
Jessica Rauch ${ }^{1}$ Peter Sothmann ${ }^{1,2,3}$. Cassandra Aldrich ${ }^{1} \cdot$ Ben Hogan $^{1} \cdot$ Ellis Owusu-Dabo ${ }^{4,5}$. Jürgen May ${ }^{1}$. \\ Daniel Eibach ${ }^{1} \cdot$ Dennis Tappe ${ }^{1}$
}

Received: 17 November 2017 / Accepted: 24 April 2018 / Published online: 8 May 2018

(C) The Author(s) 2018

\begin{abstract}
The intracellular pathogen Rickettsia felis causes flea-borne spotted fever and is increasingly recognized as an emerging cause of febrile illness in Africa, where co-infection with Plasmodium falciparum is common. Rickettsiae invade endothelial cells. Little is known, however, about the early immune responses to infection. In this study, we characterize for the first time the cytokine profile in the acute phase of illness caused by $R$. felis infection, as well as in plasmodial co-infection, using serum from 23 febrile children $<15$ years of age and 20 age-matched healthy controls from Ghana. Levels of IL-8 (interleukin-8), IP-10 (interferon- $\gamma$-induced protein-10), MCP-1 (monocyte chemotactic protein-1), MIP-1 $\alpha$ (macrophage inflammatory protein-1 $\alpha$ ) and VEGF (vascular endothelial growth factor) were significantly elevated in $R$. felis mono-infection; however, IL-8 and VEGF elevation was not observed in plasmodial co-infections. These results have important implications in understanding the early immune responses to $R$. felis and suggest a complex interplay in co-infections.
\end{abstract}

Keywords Rickettsia felis $\cdot$ Rickettsiosis $\cdot$ Flea-borne spotted fever $\cdot$ Cytokine

\section{Introduction}

Rickettsia felis causes flea-borne spotted fever (FBSF), an acute febrile illness commonly involving headache, myalgia and rash and potentially leading to severe neurological and respiratory complications [1]. While distributed worldwide, $R$. felis infection is increasingly reported in Africa, where

Jessica Rauch and Peter Sothmann contributed equally to this work.

Jessica Rauch

rauch@bnitm.de

1 Bernhard Nocht Institute for Tropical Medicine, Bernhard-Nocht-Str. 74, 20359 Hamburg, Germany

2 Division of Tropical Medicine, 1st Department of Medicine, University Medical Center Hamburg Eppendorf, Hamburg, Germany

3 German Center for Infection Research (DZIF), Partner Site Hamburg-Borstel-Lübeck, Brunswick, Germany

4 Kumasi Centre for Collaborative Research in Tropical Medicine, Kwame Nkrumah University of Science and Technology, Kumasi, Ghana

5 School of Public Health, KNUST, Kumasi, Ghana prevalence rates of $3-15 \%$ in acute fever episodes suggest an emerging importance as a cause of febrile illness [2-5]. The obligate intracellular pathogen $R$. felis belongs to the transitional group of rickettsiae, as it shares phenotypic characteristics with members of the spotted fever group (SFG) and the typhus group (TG) [2]. Rickettsiae cause endothelial cell (EC) infection which can lead to vasculitis and bacterial dissemination [6]. The vascular permeability observed in clinical cases seems to be mediated at least in part by inflammatory cells and their mediators [7]. ECs, that are besides macrophages the major target cells for rickettsial infections [8-12], react to infection with TG and SFG rickettsia with the production of proinflammatory cytokines like IL-1 (interleukin-1), IL-6 and TNF $\alpha$ (tumor necrosis factor- $\alpha$ ), chemokines like IL-8, IP-10 (interferon- $\gamma$ induced protein-10) and MCP-1 (monocyte chemotactic protein-1) and other mediators in vitro that lead to activation and recruitment of immune cells to the site of infection [8, 13-17]. IL-8, for example, promotes the recruitment of neutrophils to the site of infection and mediates angiogenesis [18-20]. IP-10 and MCP-1 are involved in the recruitment of monocytes and activated NK cells and T cells which further lead to potentiation of the inflammatory response to rickettsial infection and its clearance [21-23]. Mouse models of 
rickettsial infections further help to understand the role of cytokines in vivo. IFN $\gamma$ (interferon- $\gamma$ ) and TNF $\alpha$ have protective properties during rickettsial infection of susceptible mouse strains [24-29]. IFN $\gamma$ and TNF $\alpha$ activate intracellular bactericidal mechanisms; it was shown that IFN $\gamma$ inhibits the growth of rickettsia in various host cells [28-33]. However, in humans, the early host immune responses have not been well-characterized. In this study, we investigated serum cytokine responses in febrile children from Ghana with acute R. felis infection.

\section{Patients and methods}

Serum cytokines and chemokines were analyzed by beadbased LEGENDplex assay (BioLegend, London) from 23 febrile children $<15$ years of age (age range 0-7 years, median: 2 years) with molecularly confirmed $R$. felis infection seen at St. Michael's Hospital, Pramso, Ghana [3]. The detection limits of the LEGENDplex assay for the analyzed cytokines were as follows: bFGF (basic fibroblast growth factor: $5.03 \mathrm{pg} / \mathrm{mL}$ ), G-CSF (granulocyte colony stimulating factor: $8.77 \mathrm{pg} / \mathrm{mL}$ ), GM-CSF (granulocyte-macrophage colony stimulating factor: $9.44 \mathrm{pg} / \mathrm{mL}), \operatorname{IFN} \gamma(3.08 \mathrm{pg} / \mathrm{mL})$, IL-1B (N/A), IL-2 (3.34 pg/mL), IL-4 (4.46 pg/mL), IL-5 (3.61 pg/mL), IL-6 (2.86 pg/mL), IL-8 (5.13 pg/mL), IL-9 (1.27 pg/mL), IL-10 (2.97 pg/mL), IL-12p70 (30.33 pg/ $\mathrm{mL}), \mathrm{IL}-13$ (N/A), IL-17A (4.29 pg/mL), IL-17F (4.24 pg/ $\mathrm{mL}), \mathrm{IL}-21(1.37 \mathrm{pg} / \mathrm{mL}), \mathrm{IL}-22(5.74 \mathrm{pg} / \mathrm{mL})$, IP-10 (N/A), MCP-1 (N/A), MIP-1 $\alpha$ (macrophage inflammatory protein-1 $\alpha$ : $4.53 \mathrm{pg} / \mathrm{mL}$ ), MIP-1 $\beta$ (macrophage inflammatory protein-1B: $5.47 \mathrm{pg} / \mathrm{mL}$ ), PDGF-BB (platelet derived growth factor: N/A), RANTES (regulated on activation, normal $\mathrm{T}$ cell expressed and secreted: N/A), TNF $\alpha(1.78 \mathrm{pg} /$ $\mathrm{mL}$ ), VEGF (vascular endothelial growth factor: $7.41 \mathrm{pg} /$ $\mathrm{mL})$.

Blood samples were taken within the first week after onset of fever ( $\geq 38^{\circ} \mathrm{C}$ tympanic). Malaria microscopy and blood cultures were performed as described previously [34]. Blood cultures from the participants of this study remained sterile. A pan-rickettsial PCR targeting the glt A gene was performed on samples from patients with negative blood culture (ct-values ranged from 29 to 40). In all of these samples $R$. felis was identified by sequencing of amplicons and BLAST analysis. Details on the molecular methods are described elsewhere [3]. Eight children had a P. falciparum co-infection as evidenced by thin and thick blood films.

20 serum samples from age-matched healthy controls from the same geographical area were analyzed in comparison by the LEGENDplex assay. Thin and thick blood films for malaria, as well as PCR examinations for Plasmodium sp. and rickettsiae were negative from the control group. Both the $R$. felis infected group and the control group were serologically screened by indirect immunofluorescence tests for IgM and IgG antibodies against $R$. felis. The indirect immunofluorescence tests were performed using $R$. felis (strain California 2) grown in XTC- 2 cells. None of the subjects or controls were positive.

Statistical analysis was performed with GraphPad Prism 7 software (GraphPad Software Inc., La Jolla, USA). For comparison between the analyzed groups, 1 way ANOVA and subsequent Tukey's multiple comparisons test were used. To evaluate the fold change of cytokine concentrations between infected patients and healthy controls, the median of the cytokine concentrations from the mono-infected group and co-infected group, respectively, was divided by the median of the cytokine concentrations of the control group. In addition, ct-values of $R$. felis specific DNA was compared to cytokine concentrations of G-CSF, IL-8, IL-6, IL-10, IP-10, MCP-1, MIP-1 $\alpha$, PDGF-BB and VEGF (Spearman correlation).

\section{Results}

Serum levels of IL-8, IP-10, MCP-1, MIP- $1 \alpha$ and VEGF were significantly increased in $R$. felis mono-infections in comparison with healthy controls (Fig. 1; Table 1). Of note, the measured cytokine concentrations did not correlate with the detected $R$. felis DNA concentrations. When groups of $R$. felis infected and P. falciparum co-infected children were compared, no significant differences were observed in the expression of IP-10, MCP- 1 and MIP- $1 \alpha$. In contrast, significantly lower levels of IL-8 and VEGF were found in plasmodial co-infections compared to $R$. felis mono-infections.

IL-6, IL-10 and G-CSF showed smaller, non-significant elevations in $R$. felis mono-infection when compared to healthy controls. The expression of these cytokines was further increased, significantly for G-CSF and IL-10, in coinfected patients compared to both mono-infected patients and healthy controls. Of note, these cytokine concentrations positively correlated with the $P$. falciparum parasitemia [Spearman rank $r_{\mathrm{s}}(\mathrm{IL}-6)=0.571, p=0.151 ; r_{\mathrm{s}}(\mathrm{IL}-$ $\left.10)=0.476, p=0.243 ; r_{\mathrm{s}}(\mathrm{G}-\mathrm{CSF})=0.619, p=0.115\right]$.

PDGF levels were not found to be elevated in monoinfected patients but were significantly reduced in coinfected patients compared to healthy controls.

Serum concentrations of GM-CSF, IL-1ß, IL-2, IL-4, IL-5, IL-9, IL-12p70, IL-13, IL-17A, IL-17F, IL-21, IL-22, IFN- $\gamma$, TNF- $\alpha$, MIP-1 $1 \beta$, RANTES, and bFGF were similar in both patient groups and controls (data not shown).

\section{Discussion}

Only a few studies on cytokines and other inflammatory mediators exist for rickettsial diseases in humans. We hereby report the first data on systemic inflammatory responses in 

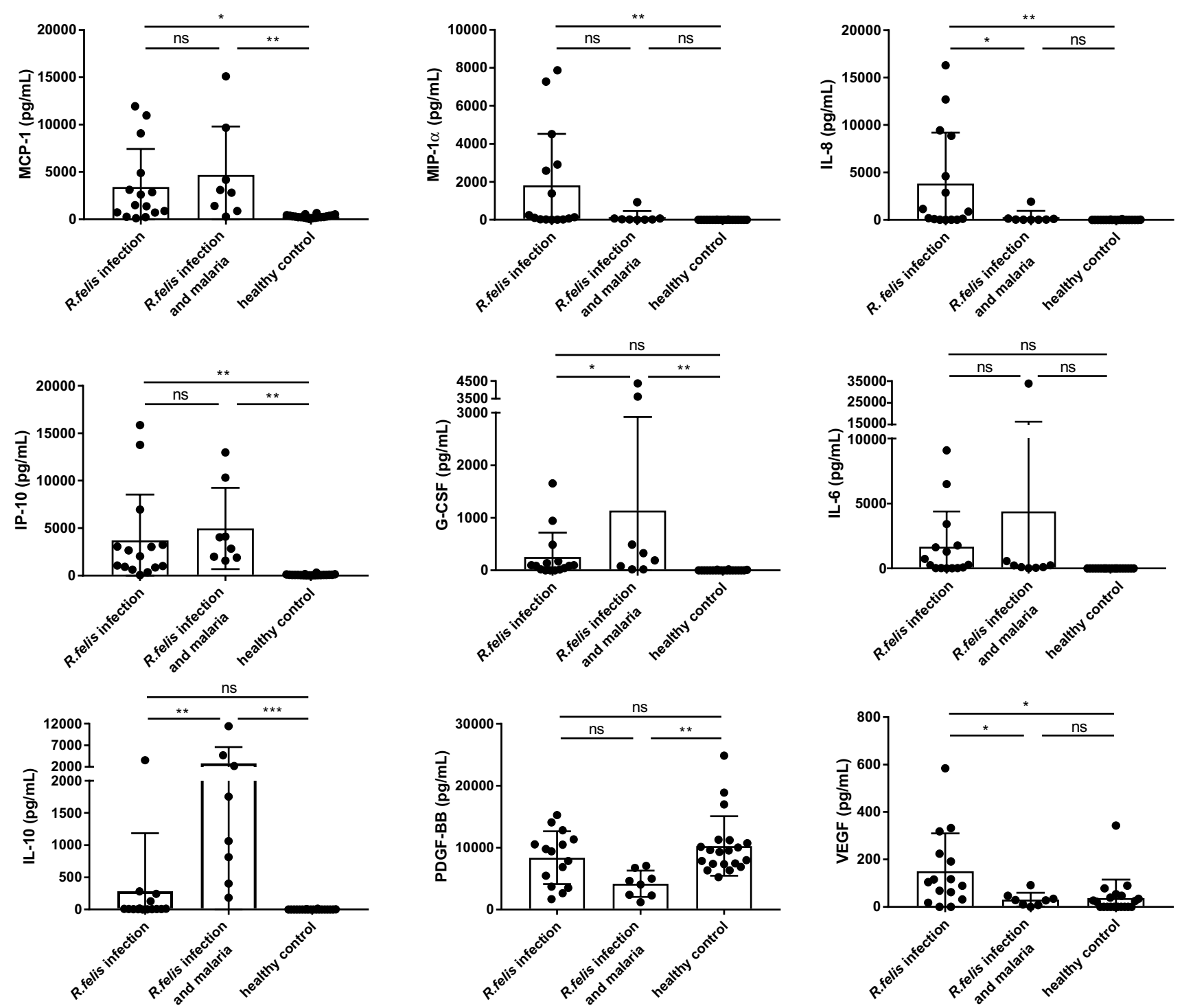

Fig. 1 Cytokine and chemokine levels in sera from children during the first week of $R$. felis infection. 15 sera from $R$. felis infected children, 8 sera from $P$. falciparum co-infected children and 20 sera from healthy children without rickettsial disease or malaria were analyzed in parallel by bead-based LEGENDplex assay. Data are expressed as

the acute phase of FBSF. Although DNA of $R$. felis has also been found on the skin of healthy individuals [35] and in blood specimens from afebrile persons [36, 37], the negative blood cultures in all $R$. felis infected children examined in our study and the negative blood films for malaria in the specified $R$. felis mono-infected subgroup of our investigation underscore that $R$. felis is the causative agent of illness in our study participants. The fact that $R$. felis plays a role as a pathogen in humans is, also, confirmed by various reports [38-41]. The absence of rickettsial antibodies in the children examined here has been repeatedly reported in patients with PCR-diagnosed $R$. felis infection and is in line mean \pm SD. Statistical analyses was performed with 1 way ANOVA and subsequent Tukey's multiple comparisons test. Asterisks indicate statistically significant differences $\left({ }^{*} p<0.05, \quad * * p<0.01\right.$, $* * * p<0.001)$

with findings of late seroconversion in rickettsial disease in general [40-45].

Levels of IL-8, IP-10, MCP-1, MIP-1 $\alpha$ and VEGF were significantly elevated in $R$. felis mono-infection. These chemokines attract immune cells to sites of infection and likely reflect initial host responses to $R$. felis. In line with that, elevations of IL- 8 and MIP- $1 \alpha$ have been reported in the acute phase of African tick-bite fever (ATBF) and Mediterranean spotted fever (MSF) caused by $R$. africae and $R$. coronii, respectively [46-48]. IL-8, and also IL-6, may play a role in the development of vasculitis resulting from the infection of endothelial cells by mediating the production 
Table 1 Cytokine changes in infected patients in comparison to healthy controls

\begin{tabular}{llll}
\hline Cytokine & \multicolumn{2}{l}{$\begin{array}{l}\text { Median cytokine concentration }(\mathrm{pg} / \mathrm{mL}) \text { (fold change to } \\
\text { healthy control) }\end{array}$} \\
\cline { 2 - 4 } & Healthy control & $R$. felis infected & $\begin{array}{l}\text { R. felis } \\
\text { infected + malaria }\end{array}$ \\
\hline IL-6 & 0 & $284.6(\mathrm{NC})$ & $169.0(\mathrm{NC})$ \\
IL-8 & 6.2 & $873.6(141.0)$ & $39.3(6.3)$ \\
IL-10 & 0 & $7.6(\mathrm{NC})$ & $1409.0(\mathrm{NC})$ \\
IP-10 & 71.6 & $2042.4(28.5)$ & $3443.7(48.1)$ \\
G-CSF & 0 & $85.1(\mathrm{NC})$ & $259.1(\mathrm{NC})$ \\
MCP-1 & 256.1 & $1491.8(5.8)$ & $2949.0(11.5)$ \\
MIP-1 $\alpha$ & 0 & $135.5(\mathrm{NC})$ & $27.5(\mathrm{NC})$ \\
PDGF-BB & 9419.8 & $9418.9(1.0)$ & $4337.8(0.5)$ \\
VEGF & 10.8 & $104.5(9.7)$ & $28.4(2.6)$ \\
\hline
\end{tabular}

The median cytokine concentrations and the changes between healthy controls and patients were calculated

$N C$ not calculable

of acute phase proteins [49]. The levels of IL-6, IL-10 and G-CSF were elevated in mono-infection and increased further in co-infection. Since both IL-6 and IL-10 have been found to be up-regulated in ATBF and MSF as well as IL-10 in malaria, these results suggest common effects of $R$. felis and $P$. falciparum [47, 48, 50, 51]. In contrast, significantly lower levels of IL-8 and VEGF in plasmodial co-infections as compared to $R$. felis mono-infections may indicate opposing effects of $R$. felis and P. falciparum. Increased IFN- $\gamma$ and TNF- $\alpha$ levels, as reported in patients with Japanese spotted fever, ATBF and MSF [6, 47, 48, 52], were not detectable in $R$. felis infected patients. However, this does not exclude a role for IFN- $\gamma$ or TNF- $\alpha$ in clearing $R$. felis infection at a later point in time.

In our study, immune responses of children towards an infection were determined. Several studies have demonstrated not only diminished humoral responses in children [53] but have also suggested that cell-mediated immunity is not fully developed in children [54]. Furthermore, cytokine production was shown to be reduced in children compared to adults. Keeping this in consideration and the opportunity that children in the median age of 2 years are infected for the first time with these pathogens, immune responses in adults could markedly differ from those of the children. Since children represent a particular vulnerable group, it is even more important to be able to make an early diagnosis to treat them adequately.

The data presented, characterizing cytokine profiles during the first week of infection with $R$. felis, offer new insights in understanding early host immune responses in FBSF and suggest a complex interplay in $R$. felis and $P$. falciparum co-infections. Further studies, such as $\mathrm{T}$ cell and antibody analyses are needed to shed more light on the immune responses during $R$. felis infection.

Acknowledgements We thank Doris Winter for her excellent technical assistance.

Funding No financial support or funding was received for this study.

\section{Compliance with ethical standards}

Conflict of interest All authors declare no conflicts of interest. No author has a commercial or other association that might pose a conflict of interest (e.g., pharmaceutical stock ownership, consultancy, advisory board membership, relevant patents, or research funding).

Ethical approval For this type of study formal consent is not required.

Open Access This article is distributed under the terms of the Creative Commons Attribution 4.0 International License (http://creativeco mmons.org/licenses/by/4.0/), which permits unrestricted use, distribution, and reproduction in any medium, provided you give appropriate credit to the original author(s) and the source, provide a link to the Creative Commons license, and indicate if changes were made.

\section{References}

1. Angelakis E, Mediannikov O, Parola P, Raoult D (2016) Rickettsia felis: the complex journey of an emergent human pathogen. Trends Parasitol 32(7):554-64

2. Brown LD, Macaluso KR (2016) Rickettsia felis, an emerging flea-borne rickettsiosis. Curr Trop Med Rep 3:27-39

3. Sothmann P, Keller C, Krumkamp R, Kreuels B, Aldrich C, Sarpong $\mathrm{N}$ et al (2017) Rickettsia felis infection in febrile children, Ghana. Am J Trop Med Hyg 96(4):783-785

4. Richards AL, Jiang J, Omulo S, Dare R, Abdirahman K, Ali A et al (2010) Human infection with Rickettsia felis, Kenya. Emerg Infect Dis 16(7):1081-1086

5. Socolovschi C, Mediannikov O, Sokhna C, Tall A, Diatta G, Bassene $\mathrm{H}$ et al (2010) Rickettsia felis-associated uneruptive fever, Senegal. Emerg Infect Dis 16(7):1140-1142

6. Sahni SK, Narra HP, Sahni A, Walker DH (2013) Recent molecular insights into rickettsial pathogenesis and immunity. Future Microbiol 8(10):1265-1288

7. Mansueto P, Vitale G, Di Lorenzo G, Arcoleo F, Mansueto S, Cillari E (2008) Immunology of human rickettsial diseases. J Biol Regul Homeost Agents 22(2):131-139

8. Sahni SK, Rydkina E (2009) Host-cell interactions with pathogenic Rickettsia species. Future Microbiol 4(3):323-39

9. Walker DH, Popov VL, Wen J, Feng HM (1994) Rickettsia conorii infection of $\mathrm{C} 3 \mathrm{H} / \mathrm{HeN}$ mice. A model of endothelial-target rickettsiosis. Lab Invest 70(3):358-68

10. Osterloh A, Papp S, Moderzynski K, Kuehl S, Richardt U, Fleischer B (2016) Persisting Rickettsia typhi causes fatal central nervous system inflammation. Infect Immun 84(5):1615-1632

11. Papp S, Moderzynski K, Rauch J, Heine L, Kuehl S, Richardt U et al (2016) Liver necrosis and lethal systemic inflammation in a murine model of Rickettsia typhi infection: role of neutrophils, macrophages and NK cells. PLoS Negl Trop Dis 10(8):e0004935

12. Walker DH, Hudnall SD, Szaniawski WK, Feng HM (1999) Monoclonal antibody-based immunohistochemical diagnosis of 
rickettsialpox: the macrophage is the principal target. Mod Pathol 12(5):529-33

13. Clifton DR, Rydkina E, Huyck H, Pryhuber G, Freeman RS, Silverman DJ et al (2005) Expression and secretion of chemotactic cytokines IL-8 and MCP-1 by human endothelial cells after Rickettsia rickettsii infection: regulation by nuclear transcription factor NF-kappaB. Int J Med Microbiol 295(4):267-78

14. Kaplanski G, Teysseire N, Farnarier C, Kaplanski S, Lissitzky JC, Durand JM et al (1995) IL-6 and IL-8 production from cultured human endothelial cells stimulated by infection with Rickettsia conorii via a cell-associated IL-1 alpha-dependent pathway. J Clin Invest 96(6):2839-2844

15. Sporn LA, Marder VJ (1996) Interleukin-1 alpha production during Rickettsia rickettsii infection of cultured endothelial cells: potential role in autocrine cell stimulation. Infect Immun 64(5):1609-1613

16. Bechah Y, Capo C, Raoult D, Mege JL (2008) Infection of endothelial cells with virulent Rickettsia prowazekii increases the transmigration of leukocytes. J Infect Dis 197(1):142-147

17. Rydkina E, Sahni A, Silverman DJ, Sahni SK (2007) Comparative analysis of host-cell signalling mechanisms activated in response to infection with Rickettsia conorii and Rickettsia typhi. J Med Microbiol 56(Pt 7):896-906

18. Baggiolini M, Clark-Lewis I (1992) Interleukin-8, a chemotactic and inflammatory cytokine. FEBS Lett 307(1):97-101

19. Valbuena G, Walker DH (2009) Infection of the endothelium by members of the order Rickettsiales. Thromb Haemost 102(6): 1071-1079

20. Li A, Dubey S, Varney ML, Dave BJ, Singh RK (2003) IL-8 directly enhanced endothelial cell survival, proliferation, and matrix metalloproteinases production and regulated angiogenesis. J Immunol 170(6):3369-3376

21. Deshmane SL, Kremlev S, Amini S, Sawaya BE (2009) Monocyte chemoattractant protein-1 (MCP-1): an overview. J Interferon Cytokine Res 29(6):313-26

22. Shi C, Pamer EG (2011) Monocyte recruitment during infection and inflammation. Nat Rev Immunol 11(11):762-74

23. Groom JR, Luster AD (2011) CXCR3 ligands: redundant, collaborative and antagonistic functions. Immunol Cell Biol 89(2):207-15

24. Walker DH, Popov VL, Feng HM (2000) Establishment of a novel endothelial target mouse model of a typhus group rickettsiosis: evidence for critical roles for gamma interferon and CD8 T lymphocytes. Lab Invest 80(9):1361-1372

25. Li H, Jerrells TR, Spitalny GL, Walker DH (1987) Gamma interferon as a crucial host defense against Rickettsia conorii in vivo. Infect Immun 55(5):1252-1255

26. Walker DH, Olano JP, Feng HM (2001) Critical role of cytotoxic $\mathrm{T}$ lymphocytes in immune clearance of rickettsial infection. Infect Immun 69(3):1841-1846

27. Feng HM, Popov VL, Walker DH (1994) Depletion of gamma interferon and tumor necrosis factor alpha in mice with Rickettsia conorii-infected endothelium: impairment of rickettsicidal nitric oxide production resulting in fatal, overwhelming rickettsial disease. Infect Immun 62(5):1952-1960

28. Moderzynski K, Heine L, Rauch J, Papp S, Kuehl S, Richardt U et al (2017) Cytotoxic effector functions of T cells are not required for protective immunity against fatal Rickettsia typhi infection in a murine model of infection: role of TH1 and TH17 cytokines in protection and pathology. PLoS Negl Trop Dis 11(2):e0005404

29. Moderzynski K, Papp S, Rauch J, Heine L, Kuehl S, Richardt $\mathrm{U}$ et al (2016) CD4+ T cells are as protective as CD8+ T cells against Rickettsia typhi infection by activating macrophage bactericidal activity. PLoS Negl Trop Dis 10(11):e0005089
30. Feng HM, Walker DH (1993) Interferon-gamma and tumor necrosis factor-alpha exert their antirickettsial effect via induction of synthesis of nitric oxide. Am J Pathol 143(4):1016-1023

31. Turco J, Winkler HH (1984) Effect of mouse lymphokines and cloned mouse interferon-gamma on the interaction of Rickettsia prowazekii with mouse macrophage-like RAW264.7 cells. Infect Immun 45(2):303-308

32. Turco J, Winkler HH (1986) Gamma-interferon-induced inhibition of the growth of Rickettsia prowazekii in fibroblasts cannot be explained by the degradation of tryptophan or other amino acids. Infect Immun 53(1):38-46

33. Chan ED, Riches DW (1998) Potential role of the JNK/SAPK signal transduction pathway in the induction of iNOS by TNFalpha. Biochem Biophys Res Commun 253(3):790-796

34. Sothmann P, Krumkamp R, Kreuels B, Sarpong N, Frank C, Ehlkes L et al (2015) Urbanicity and paediatric bacteraemia in Ghana-a case-control study within a rural-urban transition zone. PLoS One 10(9):e0139433

35. Mediannikov O, Socolovschi C, Million M, Sokhna C, Bassene H, Diatta G et al (2014) Molecular identification of pathogenic bacteria in eschars from acute febrile patients, Senegal. Am J Trop Med Hyg 91(5):1015-1019

36. Maina AN, Knobel DL, Jiang J, Halliday J, Feikin DR, Cleaveland S et al (2012) Rickettsia felis infection in febrile patients, western Kenya, 2007-2010. Emerg Infect Dis 18(2):328-31

37. Mourembou G, Lekana-Douki JB, Mediannikov O, Nzondo SM, Kouna LC, Essone JC et al (2015) Possible role of Rickettsia felis in acute febrile illness among children in Gabon. Emerg Infect Dis 21(10):1808-1815

38. Zavala-Castro J, Zavala-Velazquez J, Walker D, Perez-Osorio J, Peniche-Lara G (2009) Severe human infection with Rickettsia felis associated with hepatitis in Yucatan, Mexico. Int J Med Microbiol 299(7):529-33

39. Zavala-Velazquez J, Laviada-Molina H, Zavala-Castro J, PerezOsorio C, Becerra-Carmona G, Ruiz-Sosa JA et al (2006) Rickettsia felis, the agent of an emerging infectious disease: report of a new case in Mexico. Arch Med Res 37(3):419-22

40. Zavala-Velazquez JE, Ruiz-Sosa JA, Sanchez-Elias RA, Becerra-Carmona G, Walker DH (2000) Rickettsia felis rickettsiosis in Yucatan. Lancet 356(9235):1079-1080

41. Mediannikov O, Fenollar F, Bassene H, Tall A, Sokhna C, Trape JF et al (2013) Description of "yaaf", the vesicular fever caused by acute Rickettsia felis infection in Senegal. J Infect 66(6):536-40

42. Mediannikov O, Diatta G, Fenollar F, Sokhna C, Trape JF, Raoult D. Tick-borne rickettsioses, neglected emerging diseases in rural Senegal. PLoS Negl Trop Dis. 2010;4(9)

43. Zavala-Velazquez JE, Yu XJ, Walker DH (1996) Unrecognized spotted fever group rickettsiosis masquerading as dengue fever in Mexico. Am J Trop Med Hyg 55(2):157-159

44. Fournier PE, Jensenius M, Laferl H, Vene S, Raoult D (2002) Kinetics of antibody responses in Rickettsia africae and Rickettsia conorii infections. Clin Diagn Lab Immunol 9(2):324-328

45. La Scola B, Raoult D (1997) Laboratory diagnosis of rickettsioses: current approaches to diagnosis of old and new rickettsial diseases. J Clin Microbiol 35(11):2715-2727

46. Damas JK, Davi G, Jensenius M, Santilli F, Otterdal K, Ueland T et al (2009) Relative chemokine and adhesion molecule expression in Mediterranean spotted fever and African tick bite fever. J Infect 58(1):68-75

47. Jensenius M, Ueland T, Fournier PE, Brosstad F, Stylianou E, Vene $S$ et al (2003) Systemic inflammatory responses in African tick-bite fever. J Infect Dis 187(8):1332-1336

48. Vitale G, Mansueto S, Gambino G, Mocciaro C, Spinelli A, Rini GB et al (2001) The acute phase response in Sicilian patients with 
boutonneuse fever admitted to hospitals in Palermo, 1992-1997. J Infect 42(1):33-9

49. Mansueto P, Vitale G, Cascio A, Seidita A, Pepe I, Carroccio A et al (2012) New insight into immunity and immunopathology of Rickettsial diseases. Clin Dev Immunol 2012:967852

50. Noone C, Parkinson M, Dowling DJ, Aldridge A, Kirwan P, Molloy SF et al (2013) Plasma cytokines, chemokines and cellular immune responses in pre-school Nigerian children infected with Plasmodium falciparum. Malar J 12:5

51. Peyron F, Burdin N, Ringwald P, Vuillez JP, Rousset F, Banchereau J (1994) High levels of circulating IL-10 in human malaria. Clin Exp Immunol 95(2):300-303
52. Cillari E, Milano S, D’Agostino P, Arcoleo F, Stassi G, Galluzzo A et al (1996) Depression of CD4 T cell subsets and alteration in cytokine profile in boutonneuse fever. J Infect Dis 174(5):1051-1057

53. Rijkers GT, Sanders LA, Zegers BJ (1993) Anti-capsular polysaccharide antibody deficiency states. Immunodeficiency 5(1):1-21

54. Lilic D, Cant AJ, Abinun M, Calvert JE, Spickett GP (1997) Cytokine production differs in children and adults. Pediatr Res 42(2):237-40 